\title{
Central Nervous System Vasculitis in Rheumatoid Arthritis
}

\author{
PETER WATSON, JOHN FEKÉTE AND JOHN DECK
}

\begin{abstract}
SUMMARY: The history of a patient with rheumatoid arthritis and necrotizing vasculitis affecting only the central nervous system is reported. Clinical and pathological involvement by this process was present in both cerebral hemispheres, the pons and spinal cord. Review of the literature revealed that cerebral vasculitis in rheumatoid arthritis has been reported rarely and spinal cord vasculitis not at all.
\end{abstract}

RESUMÉ: Nous rapportons l'histoire clinique d'un patient atteint d'arthrite rheumatoide et de vasculite nécrosante touchant seulement le système nerveux central. L'atteinte clinique et pathologique se manifestait aux deux hémisphères cérébraux, à la protubérance et à la moelle. Une revue de la littérature montre que la vasculite cérébrale de l'arthrite rhumatoide. ne fut que rarement rapportée, cependant qu'il n'existe aucun rapport d'une vasculite de la moelle.

From the: Departments of Neurology and Pathology, The Mississauga and Toronto Western Hospitals.

Reprint requests to: Dr. Peter Watson, 3025 Hurontario Street, Suite 504, Mississauga, Ontario LSA 2H1, Canada.
INTRODUCTION

The neurological complications of rheumatoid disease usually do not affect the central nervous system. However, atlantoaxial subluxation may result in spinal cord compression. Rheumatoid nodules of the dura mater may be found at post mortem but usually do not produce symptoms (Contin, 1966; Ellman, 1954; Maher, 1954; Mikkelson, 1955). Rheumatoid pachymeningitis of the spinal dura may compress the spinal cord (Gutman, 1963). Rarely, cerebral vasculitis has been reported in association with a generalized vasculitis resembling polyarteritis nodosa (Pirani, 1951; Sokoloff, 1957; Johnson, 1959; Steiner, 1959; Ouyang, 1967). More rarely, vasculitis confined to the central nervous system has been reported (Johnson, 1959; Steiner, 1959). This vasculitis has been related to corticosteroid therapy (Johnson, 1959).

\section{CASE REPORT}

A 54 year old woman presented with the sudden onset of expressive dysphasia, left sided peripheral facial palsy and left sixth nerve palsy. Cerebellar ataxia of the left arm and leg and a moderate right hemiparesis were present. Anatomical localization of the recent neurological involvement was therefore to the left frontal lobe and left pons. These findings were superimposed upon a residual neurological deficit from a spinal cord lesion occurring six months prior to admission. At that time, she had developed bilateral pyramidal-type leg weakness, with clinical localization to the mid thoracic spinal cord and a negative myelogram.

The patient had a 20 year history of chronic rheumatoid arthritis with typical hand deformity and rheumatoid nodules on the extensor surface of her forearms. Recently, the disease had been quiescent. She had never been on corticosteroids.

The patient had a stormy clinical course which was marked by aspiration and bacterial pneumonia. There was initial neurologic improvement with high doses of corticosteroids of $100 \mathrm{mg}$. daily, but pulmonary infection supervened and the steroids were gradually tapered with concomittant neurological deterioration. The patient died from pneumonia six months after admission.

Pertinent laboratory findings at the time of admission included an ESR ranging from $80-120 \mathrm{~mm} / \mathrm{hr}$. The latex fixation test was positive in a dilution of $1 / 640$. L.E. cells were negative. The fluorescent antinuclear factor test was negative. Serum protein electrophoresis was normal. The CSF protein was 117 with a normal cell count. Routine blood count, BUN, blood sugar, serum creatinine, SGOT, SGPT, alkaline phosphatase, bilirubin, urinalysis, electrocardiograms and chest $\mathrm{x}$-ray were normal.

\section{Post Mortem Findings:}

The deceased was a well nourished, middle-aged white female. Both hands showed marked deformities which were consistent with the diagnosis of chronic rheumatoid arthritis. Subcutaneous nodules were present on the extensor surface of the forearms. The brain weighed 1530 grams. An old hematoma of $1 \times 3 \mathrm{~cm}$. was present in the left frontal lobe (Figure 1). In the right frontal lobe, almost symmetrically opposite to the old left sided hematoma, a $3 \times 4 \mathrm{~cm}$. recent hematoma was present with extension into the subarachnoid space over that hemisphere. (Figure 1). In 


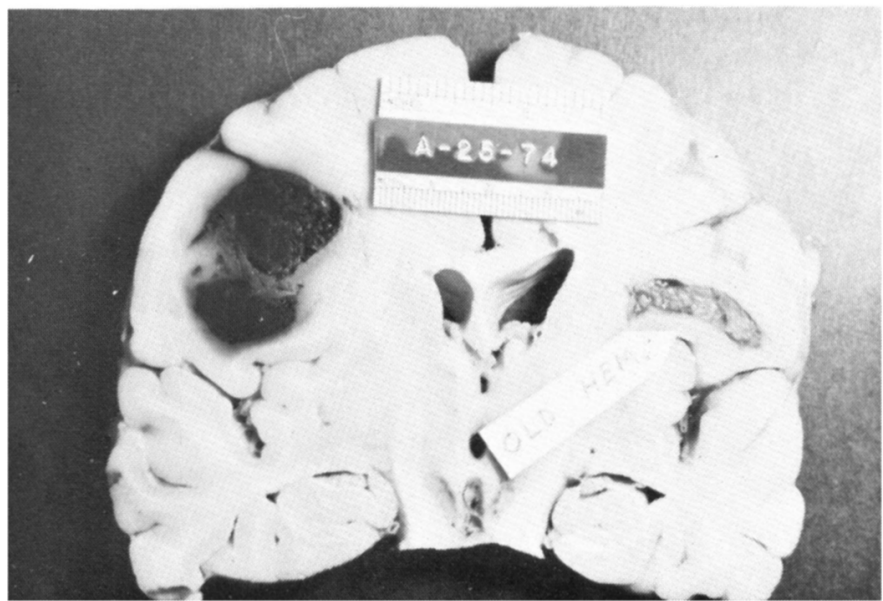

Figure l-Recent hematoma of the right frontal lobe and organizing hematoma of the left frontal lobe of the brain.

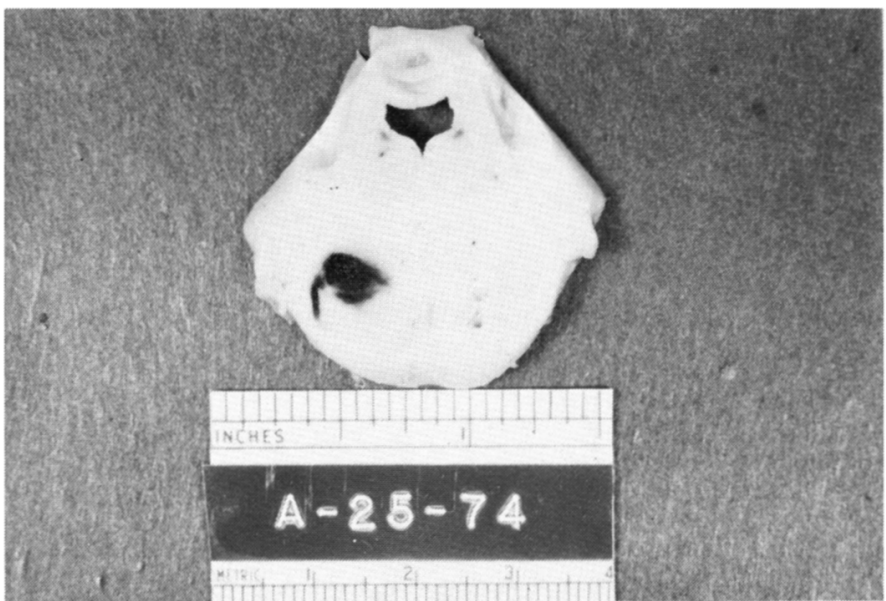

Figure 2-Recent hematoma in the right pons. Older lesion in left pons. the right pons a recent hemorrhage was present measuring $5 \times 5 \mathrm{~mm}$. In the left pons an old hemorrhage was present with a small cyst measuring $2 \times 2 \mathrm{~mm}$. (Figure 2). The spinal cord appeared grossly normal.

Both lungs showed evidence of confluent bronchopneumonia.

Microscopic examination of the right frontal lobe of the brain confirmed the presence of a recent hematoma. The left frontal lobe contained an older hematoma with many macrophages and reactive astrocytes. The small and medium-sized arteries supplying the hemorrhagic areas of the brain showed necrotizing vasculitis. Similar changes were present in the cerebellum, the pons and the para-ventricular areas of the hemispheres, No antinuclear factor was demonstrated in the necrotic media of the affected arteries by immuno-fluorescent technique. The mid thoracic spinal cord showed evidence of necrotizing vasculitis of the arterioles in the subarachnoid space (Figure 3). The walls of the arterioles showed an infiltrate of mononuclear cells, chiefly in the adventitia and fibrinoid necrosis. The lumina of some vessels were completely occluded by organized, or partly organized thrombi. (Figure 4). Staining with PTAH further demonstrated the presence of fibrinoid necrosis (Figure 5). Similar but less severe changes were found in cervical and lumbar segments of the cord.

Vasculitis was not found elsewhere in the body.

\section{COMMENT}

Necrotizing arteritis is encountered in many clinical settings and diseases. Numerous attempts have been made to classify these acute angiitides. The most recent is that of Wigley (1970). By exclusion of other causes by clinical, laboratory and autopsy findings, we can conclude that the vasculitis in our case was associated with rheumatoid disease.

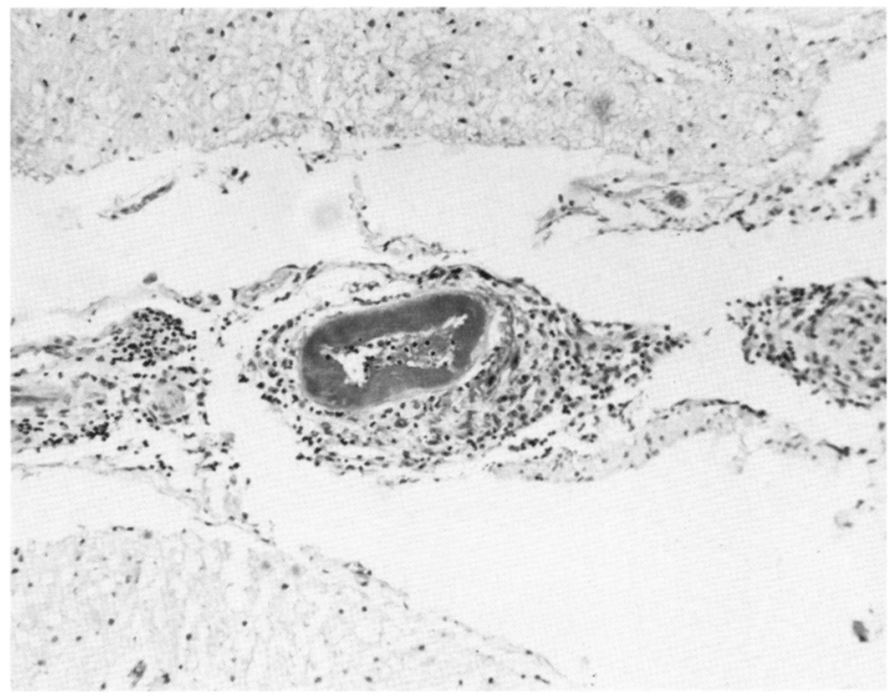

Figure $3 A-$ Necrotizing vasculitis of an arteriole of the subarachnoid space of the mid-thoracic spinal cord. (H \& $E$ Stain 40x).

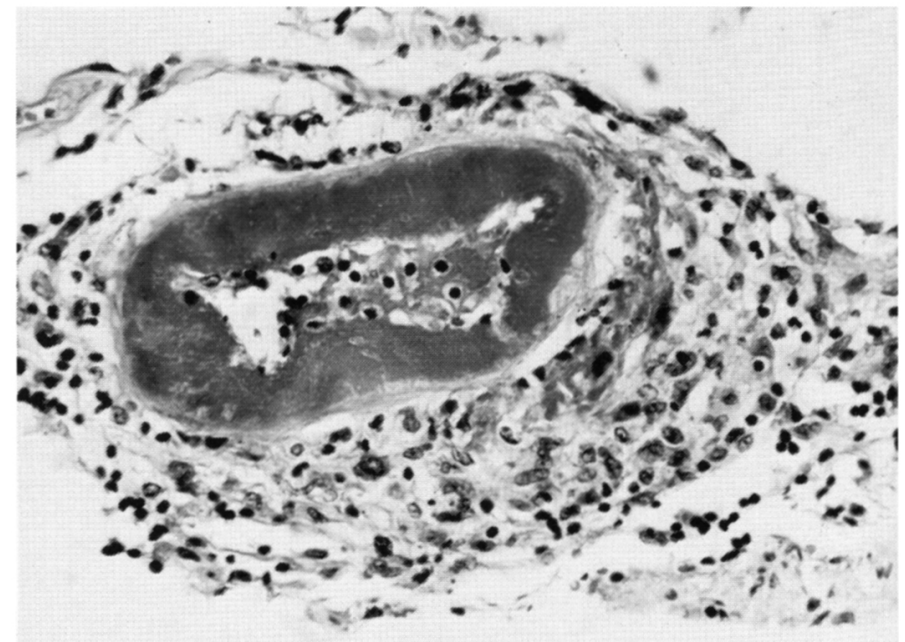

Figure $3 B-$ Necrotizing vasculitis of an arteriole of the subarachnoid space of the mid-thoracic spinal cord. (H \& $E$ Stain $\times 100$ ). 


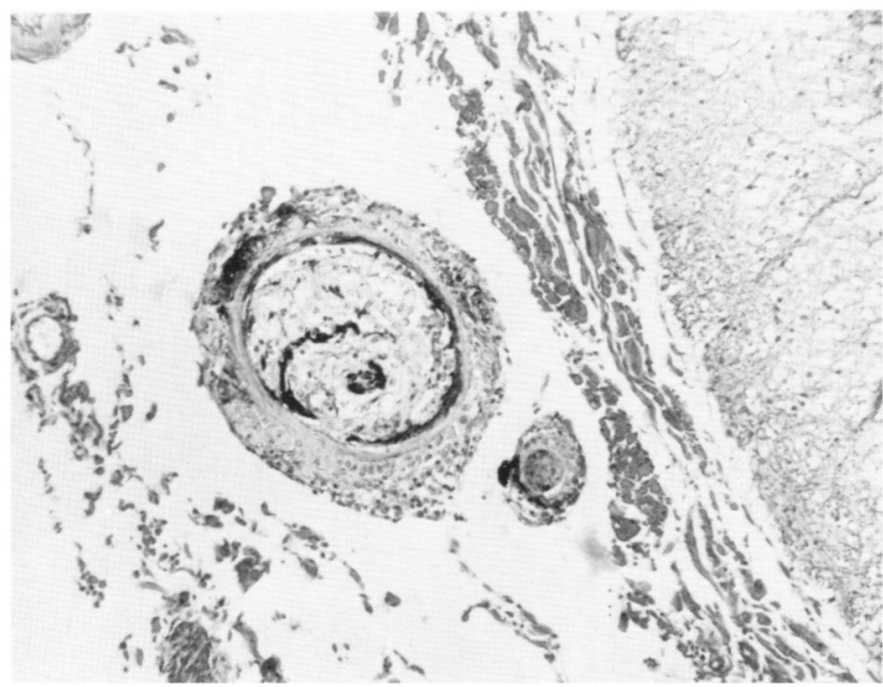

Figure 4-Small arteriole of the thoracic spinal cord with necrotizing vasculitis and thrombus formation. ( $H$ \& $E$ Stain $40 x)$.

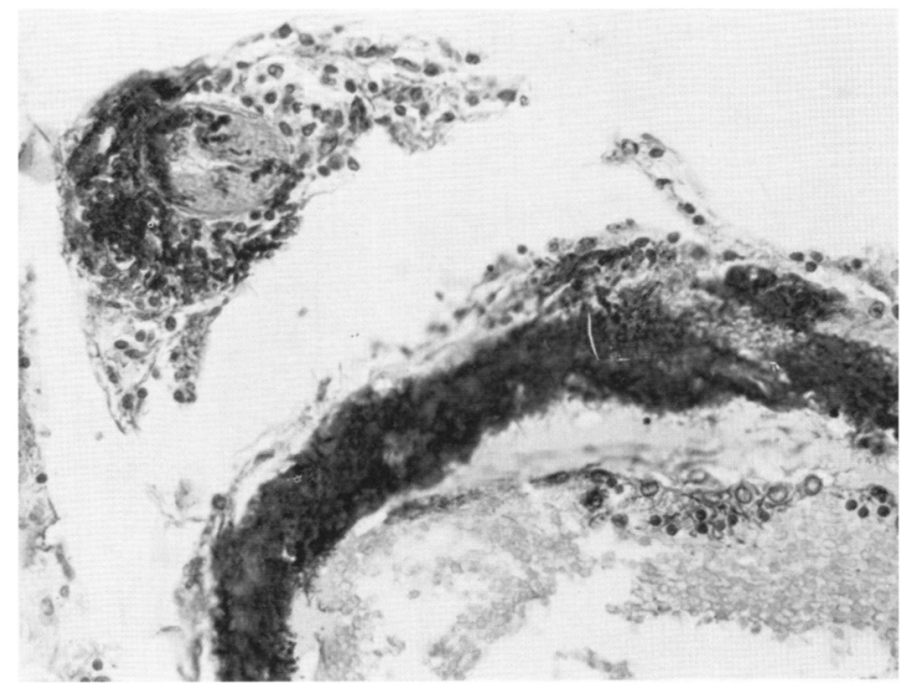

Figure 5-Fibrinoid necrosis in an arteriole of the subarachnoid space of the mid-thoracic spinal cord. (PTAH stain $\times 100$ ).
According to Boyle and Buchanan (1971), there are two main types of vasculopathy in rheumatoid disease. One is an inflammatory polyarteritis, and the other is a non-inflammatory intimal hypertrophy.

More recently, it has been suggested that intimal hypertrophy may be merely a late stage of arteritis in which the inflammatory changes have subsided. Thus, the variation in histopathologic features may reflect differing intervals between the time of onset of vasculitis and the time of biopsy or autopsy. (Glass. 1976)

Vasculitis produces, most commonly, peripheral neuropathy, skin ulceration, bowel perforation and coronary occlusion. It tends to be associated with nodules, pericarditis, episcleritis and positive LE cell preparations. Pathologically, all layers of the vessel walls are involved. The lesions may be indistinguishable from polyarteritis nodosa. It has been thought in the past that vasculitis in rheumatoid disease has been related to fluctuations in steroid therapy. Johnson, (1959).

However, this case, like two others in the literature. Pirani (1951) and Ramos (1975), was not treated with corticosteroids, indicating that this therapy was not a factor in the precipitation of the vasculitis and that the vasculitis was related in some other way to the rheumatoid arthritis.

Although immunopathologic studies are few, $\operatorname{IgG}, \operatorname{Ig} M$ and $C 3$ protein have been noted in the walls of involved arteries in some reported cases (Conn. 1972). Patients with rheumatoid arthritis characterized by nodular and erosive disease and high titres of rheumatoid factor are particularly prone to develop arteritis (Mongan, 1969). These data suggest a role for circulating immune complexes in the pathogenesis of some arteritic lesions (Glass, 1976).

Including the case of Ramos and Mandybur (1975) and their review of the literature, there are seven reports of cerebral vasculitis with pathological studies in patients with rheumatoid arthritis. In all of the cases, necrotizing intracranial vasculitis was present. In four of these cases, the cerebral arteritis was part of generalized vasculitis, similar to polyarteritis nodosa. In only three cases was the vasculitis limited to the brain (Steiner, 1959; Ouyang, 1967; Ramos, 1975). Five of the seven cases had been treated with corticosteroids in varying doses.

Other studies document central nervous system dysfunction in juvenile rheumatoid arthritis clinically (Jan, 1972) and radiologically (Sievers, 1968), but lack pathologic studies confirming vasculitis.
Of interest is the apparent rarity of cerebral vasculitis as indicated by the seven reported cases and of the selective and severe cerebral involvement in four cases, including this report.

Spinal cord vasculitis with rheumatoid disease has never been reported previously.

It is suggested that in the instance of any patient with rheumatoid arthritis presenting with central nervous system dysfunction that cerebral and spinal cord vasculitis should be considered diagnostic possibilities. even when the arthritis appears quiescent and in the absence of extracerebral organ involvement. The diagnosis may, of necessity, be a diagnosis of exclusion.

\section{REFERENCES}

BOYLE. J. A.. BUCHANAN. W. W. (197I) Clinical Rheumatology First Ed.. London. William Clowes \& Sons Lid.. p. 136.

CONN. D. L.. MCDUFFIE. F. C.. DYCK. P. J. (1972). Immunopathologic study of sural nerves in rheumatoid arthritis. Arthritis and Rheumatism 15. p. 135-143.

CONTIN. J. U., OKA. N. (1966) Unusual Cardiac Pulmonary and Meningeal Involvement in Rheumatoid Arthritis. Chest 49. p. 552-556.

ELLMAN. P., CULKOWICZ, L., ELWOOD, J. S.. (1954) Widespread Serous Membrane Involvement by Rheumatoid Nodules. J. Clin. Pathol., 7. p. 239-244.

GLASS, D., SOTER, N. A. SCHUR. P. H. (1976). Rheumatoid vasculitis. Arthritis and Rheumatism 19. p. 950-952. 
GUTMAN, I., HABLE, K. (1963). Rheumatoid Pachymeningitis, Neurology 13, p. 901-905.

JAN, J. E., HILL, R. H., LOW, M. D. (1972). Cerebral Complications in Juvenile

JOHNSON, R. L., SMYTH, C. J., HOLT, G. W., (1959) Steroid Therapy and Vascular Lesions in Rheumatoid Arthritis, Arthritis Rheum. 2, p. 224-249.

MAHER, J. A., (1954) Dural Nodules in Rheumatoid Arthritis. Report of a Case, Arch. Pathol. 58, p. 354-359.

MIKKELSON, W. M., DUFF, I. F., ROBINSON, W. D., (1955) Unusual Manifestations of Rheumatoid Nodules: Report of Three Cases, J. Mich. Med. Soc., 54, p. 292-297.
MONGAN, E. S., CASS, R. M., JACOX, R. F., et al. (1969). A study of the relation of seronegative and seropositive rheumatoid arthritis to each other and to necrotizing vasculitis. Am. J. Med. 47: 23-35.

OUYANG, R., MICHELL, D. M., ROZDILSKY, B. (1967) Central Nervous System Involvement in Rheumatoid Desease: Report of a case., Neurology 17, p. 1099-1105.

PIRANI, C. L.. BENNETT, G. A., (1951) Rheumatoid Arthritis: A report of three cases progressing from childhood and emphasizing certain systemic manifestations, Bull. Hosp. Joint Dis., 12, p. 335-367.

RAMOS, M., MANDYBUR, T. I., (1975) Cerebral Vasculitis in Rheumatoid Arthritis, Arch. Neurol., 32, p. 271-275.
SIEVERS, K., MISSILA, M., SIEVERS, U. M. (1968). Cerebral Vasculitis Visualized by Angiography in Juvenile Rheumatoid Arthritis Simulating Brain Tumor., Acta. Rheumatol. Scand., 14, p. 222-232.

SOKOLOFF, L., BUNIM, J. J., (1957) Vascular Lesions in Rheumatoid Arthritis, J. Chronic Dis., 5, p. 668-687.

STEINER, J. W., GELLBLOOM, A. J., (1959) Intracranial Manifestations in two cases of Systemic Rheumatoid Disease, Arthritis Rheum. 2, p. 537-545.

WIGLEY, R. D., (1974) The Aetiology of Polyarteritis Nodosa: A review., New Zeal. Med. Journal, 71, p. 151, quoted by ROBBINS, S. L., Pathologic Basis of Disease, W. B. Saunders Co., Philadelphia, 1970, p. 236. 